\title{
RESEARCH
}

Open Access

\section{Toll-like receptor 4 agonist and antagonist lipopolysaccharides modify innate immune response in rat brain circumventricular organs}

Alejandra Vargas-Caraveo ${ }^{1,2^{*}}$, Aline Sayd ${ }^{1}$, Javier Robledo-Montaña ${ }^{1}$, Javier R. Caso ${ }^{1}$, José L. M. Madrigal ${ }^{1}$, Borja García-Bueno ${ }^{*^{*}}$ (D) and Juan C. Leza ${ }^{1}$

\begin{abstract}
Background: The circumventricular organs (CVOs) are blood-brain-barrier missing structures whose activation through lipopolysaccharide (LPS) is a starting point for TLR-driven (Toll-like receptors) neuroinflammation. The aim of this study was to evaluate in the CVO area postrema (AP), subfornical organ (SFO), and median eminence (ME), the inflammatory response to two TLR4 agonists: LPS from Escherichia coli (EC-LPS), the strongest endotoxin molecule described, and LPS from Porphyromonas gingivalis (PG-LPS), a pathogenic bacteria present in the periodontium related to neuroinflammation in neurodegenerative/psychiatric diseases. The response to LPS from the cyanobacteria Rhodobacter sphaeroides (RS-LPS), a TLR4 antagonist with an interesting anti-inflammatory potential, was also assessed.
\end{abstract}

Methods: LPSs were intraperitoneally administered to Wistar rats and, as indicatives of neuroinflammation in CVOs, the cellular localization of the nuclear factor NF-KB was studied by immunofluorescence, and microglia morphology was quantified by fractal and skeleton analysis.

Results: Data showed that EC-LPS increased NF-KB nuclear translocation in the three CVOs studied and PG-LPS only induced NF-KB nuclear translocation in the ME. RS-LPS showed no difference in NF-KB nuclear translocation compared to control. Microglia in the three CVOs showed an ameboid-shape after EC-LPS exposure, whereas PGLPS only elicited a mild tendency to induce an ameboid shape. On the other hand, RS-LPS produced a markedly elongated morphology described as "rod" microglia in the three CVOs.

Conclusions: In conclusion, at the doses tested, EC-LPS induces a stronger neuroinflammatory response than PGLPS in CVOs, which might be related to their different potency as TLR4 agonists. The non-reduction of basal NF-KB activation and induction of rod microglia by RS-LPS, a cell morphology only present in severe brain injury and infections, suggests that this molecule must be carefully studied before being proposed as an anti-inflammatory treatment for neuroinflammation related to neurodegenerative/psychiatric diseases.

Keywords: Innate immunity, Blood-brain interfaces, Bacterial infection, Microglia, Immunofluorescence

\footnotetext{
*Correspondence: a_vargas@correo.ler.uam.mx; bgbueno@med.ucm.es 'Departamento de Farmacología y Toxicología, Facultad de Medicina, Universidad Complutense de Madrid (UCM); Centro de Investigación Biomédica en Red de Salud Mental (CIBERSAM); Instituto de Investigación Sanitaria Hospital 12 de Octubre (Imas12); Instituto Universitario de Investigación en Neuroquímica UCM, Avda. Complutense s/n, 28040 Madrid, Spain

Full list of author information is available at the end of the article
}

(c) The Author(s). 2020 Open Access This article is distributed under the terms of the Creative Commons Attribution 4.0 International License (http://creativecommons.org/licenses/by/4.0/), which permits unrestricted use, distribution, and reproduction in any medium, provided you give appropriate credit to the original author(s) and the source, provide a link to the Creative Commons license, and indicate if changes were made. The Creative Commons Public Domain Dedication waiver (http://creativecommons.org/publicdomain/zero/1.0/) applies to the data made available in this article, unless otherwise stated. 


\section{Background}

Circumventricular organs (CVOs) are brain structures of the third and fourth ventricles. They are characterized by the absence of blood-brain-barrier (BBB) and are highly vascularized with fenestrations. The area postrema (AP) is present in the fourth ventricle and the subfornical organ (SFO) in the third ventricle, both of which are considered sensory CVOs by the presence of neuronal soma and terminals that sense blood and intestinal fluids and have connectivity to other brain areas with BBB [1]. Median eminence (ME) is considered a secretory CVO located in the basal hypothalamus with a fenestrated endothelium [2].

Because of the lack of BBB, CVOs are exposed to circulating LPS [3]. It has been established that these structures have basal expression levels of LPS receptors CD14 and TLR4 [4]. Recently, our group has demonstrated that lipid A and core oligosaccharide, key regions of the LPS molecule, are present in physiological conditions in AP, SFO, and ME, in constant co-localization with CD14 and TLR4 [5]. Although several studies have used intraperitoneal and cerebroventricular injections of E. coli LPS as a model of neuroinflammation $[4,6,7]$, it is important to point out that, in stress-related neuropsychiatric disorders, LPS can be detected in the bloodstream in higher concentrations than in healthy controls $[8,9]$

LPS toxicity depends on lipid A composition, in particular, the acyl chain region of the lipid A moiety from LPS is recognized by CD14 and TLR4 receptors in most cells, triggering the innate immune signaling pathway, inducing NF- $\mathrm{kB}$ nuclear translocation and, consequently, the release of pro-inflammatory cytokines and the synthesis of inducible inflammatory and oxido/nitrosative enzymes [5]. Therefore, the lipid A structure is related to its endotoxic properties, but some differences in potency have been described, depending on the microbial species, environmental conditions such as temperature and interactions with the host immune system [10-12]. For example, the lipid A moiety produced by Enterobacteriaceae, and other gram-negative aerobes, has 6 fatty acyl chains and 2 phosphates, and this is excellent for binding to TLR4/MD2 complex and promoting dimerization and activation. The TLR4 signal transduction produced by a hexaacyl lipid A, e.g., from E. coli (EC-LPS) like the one used in this study, is characterized by a strong pro-inflammatory signal leading to a high expression of tumor necrosis factor $\alpha(\mathrm{TNF}-\alpha)$, interleukin-1 $\beta$ (IL-1 $\beta)$, macrophage inflammatory protein 2 (MIP-2), interleukin $12 \mathrm{p} 40$ (IL-12 p40) and interferon $\gamma($ IFN- $\gamma$ ) [13].

Lipid A structures synthesized by other families of bacteria, with less fatty acyl chains and/or lack of 4'phosphate are considered weak TLR4 agonists or TLR4 antagonists [12, 14]. An excellent example of this is the
LPS from Porphyromonas gingivalis (PG-LPS), a weak TLR4 agonist, with a pentaacyl lipid A, less endotoxic properties compared to EC-LPS that induces the expression of TNF- $\alpha$, IL-1 $\beta$, and MIP-2, but not IL-12 p40 and IFN- $\gamma$ [13], but with significant relevance in the inflammatory response in periodontal disease. Recently, inflammation derived from periodontitis has been related to the neuroinflammation state in neurodegenerative [15] and psychiatric diseases $[16,17]$. Oral infection with $P$. gingivalis in mice can produce an impairment of learning and memory abilities by the release of proinflammatory cytokines in the brain [18], as well as depression-like behavior and a reduction of brainderived neurotrophic factor (BDNF )[19]. A PG-LPS i.p. injection in rodents can lead to impairments in learning and memory tasks, and to an increase of inflammatory cytokines (TNF- $\alpha$, IL-1 $\beta$, IL-6, and IL-8) in brain cortex and activation of microglia and astrocytes in both hippocampus and brain cortex [20].

On the other hand, a potent TLR4 antagonist in rodents and humans is the LPS synthetized by the cyanobacteria Rhodobacter sphaeroides [21]. Lipid A of RS-LPS does not induce cytokine expression because its signal transduction is not carried out; consequently, NF$\kappa \mathrm{B}$ is not translocated to the nucleus [13]. This bacterium has no relevance as a pathological microorganism; however, its LPS has been widely used as a blocker of TLR-4 to prevent inflammatory response in the presence of the highly endotoxic EC-LPS and it has been proposed as a neuroprotective strategy to prevent neuroinflammation [22, 23]. Microglial activation by EC-LPS in slices of the corpus callosum was correlated with axonal malfunction and with the accumulation of $\beta$-amyloid precursor protein in nerve fibers and a double treatment with EC-LPS and RS-LPS inhibited TLR-4 pathway activation and reversed microglial activation [24]. Using RSLPS in an experimental model of epilepsy to block TLR4 and to inhibit the release of pro-inflammatory mediators by microglia and astrocytes, excitability decreased in seizure threshold [25]. In experiments of nociception through chronic constriction injury to the sciatic nerve, the blockade of TLR-4 using RS-LPS by repeated intrathecal administration, attenuated allodynia and hyperalgesia [26]. On the contrary, in mouse primary microglia cultures, it was observed that RS-LPS can develop TLR-4 agonistic properties inducing the release of cytokines and chemokines [27].

Based on this evidence, we suggest that the presence of LPS molecules in the bloodstream derived from different gram-negative species and with distinct endotoxic properties modifies immediately the activity of the innate immune-mediated intracellular pathways in the first line of immune defense in the brain, the CVO's. The present study aimed to evaluate the effects on CVOs 
neuroinflammatory response (NF- $\mathrm{kB}$ and microglia activation) of the weak TLR4 agonist PG-LPS and the TLR4 antagonist RS-LPS in comparison with the very wellknown neuroinflammatory trigger and strongest TLR4 agonist EC-LPS.

\section{Methods}

\section{Animals}

Sixteen male Wistar Hanover rats (HsdRccHan:Wist, from Envigo, Spain), weighing 250-280 g were used. The rats were housed individually with standard temperature and humidity conditions and in a 12-h light/dark cycle (lights on at 8:00 h) with free access to food and water. All the animals were maintained under these conditions for 7 days prior to the experiment.

\section{Experimental groups and LPS administration}

Four experimental groups were used for the treatment with three different types of LPS and a control group (vehicle-injected). EC-LPS (Escherichia coli serotype 0111: B4, ref. L2630, Sigma-Aldrich, Spain), PG-LPS (Porphyromonas gingivalis ref. tlrl-pglps, InvivoGen USA) and RS-LPS (Rhodobacter sphaeroides ref. tlrlrslps, InvivoGen, USA) were dissolved in sterile $0.9 \%$ saline solution. Group sizes were previously calculated using specialized software (STATGRAPHICS Centurion XVI, UCM license). The number of animals $(n=4)$ is the one obtained when, based on previous data from our laboratory and other groups performing immunohistochemistry analysis on counting cells in CVO [28], the difference to detect is set at 3 times $(3 \times)$ the sigma, with a test potency of $80 \%$ and an alpha risk of 0.05 .

The rats were intraperitoneally injected with $0.5 \mathrm{mg} / \mathrm{kg}$ of LPS or $2 \mathrm{~mL} / \mathrm{kg}$ of saline solution, respectively. Ninety minutes later, animals were sacrificed using sodium pentobarbital (320 mg/kg i.p.).

Timing and dose of LPSs i.p. injections were chosen based on previous studies, where a non-endotoxemic dose of EC-LPS at $0.5 \mathrm{mg} / \mathrm{kg}$ was used to induce mild neuroinflammation after $90 \mathrm{~min}[29,30]$. Other relevant studies that evaluate inflammatory response in the CVOs have used EC-LPS doses from $50 \mu \mathrm{g}$ to $1 \mathrm{mg} / \mathrm{kg}$ at different times from $30 \mathrm{~min}$ to $4 \mathrm{~h}[31,32]$. Our model is an acute LPS administration and we decided to use $90 \mathrm{~min}$ to observe an immediate effect on the CVOs, the first line of brain immune defense [33]. It has been reported that after $3 \mathrm{~h}$, other structures start to develop the inflammatory response and CVOs stop their response [33].

Since there are only a few works related to the effects of PG-LPS and RS-LPS on the brain, and, to our knowledge, none of them has analyzed the inflammatory response in the CVOs, we decided to extend the same timing and dose that we have previously used for EC-
LPS to PG-LPS and RS-LPS in order to compare their effects on innate immune response.

\section{Immunohistochemistry}

Transcardial perfusion was performed through the left ventricle with $200 \mathrm{~mL}$ of saline solution, and the right atrium was opened. Next, $200 \mathrm{~mL}$ of $4 \%$ paraformaldehyde (PFA) in $0.1 \mathrm{M}$ of PBS (pH 7.4) was perfused. Brains were dissected and post-fixed in $4 \%$ PFA overnight at $4{ }^{\circ} \mathrm{C}$, then were equilibrated in $30 \%$ sucrose at $4{ }^{\circ} \mathrm{C}$ until precipitate appeared, around $48 \mathrm{~h}$. Brains were embedded in an optimum cutting temperature (O.C.T. tissue tek) and frozen at $-20{ }^{\circ} \mathrm{C}$ to obtain 15 $\mu \mathrm{m}$ coronal sections using a cryostat. Consecutive sections were obtained from the SFO (between Bregma -0.84 and $-1.08 \mathrm{~mm}$ ), ME (between Bregma -1.80 and $-2.04 \mathrm{~mm}$ ), and AP (between Bregma $-13.68 \mathrm{~mm}$ to $14.16 \mathrm{~mm}$ ) by using as reference the stereotaxic atlas of Paxinos and Watson. Sections were collected and mounted on slides with adherent coating. All brain tissue sections were maintained at $-40{ }^{\circ} \mathrm{C}$ until use.

Simultaneous double immunostaining was performed in three consecutive sections for each structure. Sections were washed with KPBS $0.02 \mathrm{M}$ for $5 \mathrm{~min}$, treated with $0.1 \mathrm{M}$ of glycine during $20 \mathrm{~min}$ to eliminate autofluorescence, two 5-min washes with KPBS, then the blocking process for $30 \mathrm{~min}$ with $10 \%$ BSA in KPBS. Incubation with primary antibodies, in KPBS containing 10\% BSA, lasted $2 \mathrm{~h}$, at room temperature. Sections were washed in KPBS three times for $5 \mathrm{~min}$ each; secondary antibody incubation was carried out for $1 \mathrm{~h}$, antibodies were diluted in KPBS ( $\mathrm{pH} 7.4$ ) containing 10\% BSA; thereafter, sections were washed three times in PBS for 5 min each, and one last wash with deionized water alone for $5 \mathrm{~min}$. Finally, 4',6-diamidino-2-phenylindole dihydrochloride (DAPI) containing Fluoroshield (Sigma Aldrich) mounting medium was added to the slides in the double immunostaining procedure. Sections were coverslipped and frozen at $-20^{\circ} \mathrm{C}$ or immediately visualized using a highperformance fluorescence microscope. Confocal images were obtained in the confocal Olympus microscope FV1200, from CAI-UCM Centro de Citometría y Microscopía de Fluorescencia.

Titration for every primary and secondary antibody was tested at different dilutions to avoid nonspecific interactions but establishing the best immunosignal. In order to corroborate if nonspecific binding of the fluorescent secondary antibodies was present, negative controls were carried out, for each antibody, using the sample protocol, instead of primary antibody incubation, tissue was maintained with blocking solution during this time. 


\section{Image analyses}

Quantification of cells with nuclear translocation and retention of NF- $\kappa B$ and number of total cells of the section with DAPI staining in AP and SFO structures were performed using the $3 \mathrm{D}$ objects counter tool for automated counting Fiji. For ME structure, quantification was made manually using the cell counter plugin software because only the area with fenestrated vessels was considered. Three consecutive sections of each CVO, from each rat, were analyzed. Images were processed to adjust brightness, contrast and merge images in the processing package "Fiji".

In each section, overlapping of red and blue fluorescent signals was considered as nuclear translocation and a red immunosignal surrounding DAPI staining was considered as NF- $\mathrm{KB}$ cytoplasmic retention, using a cell counter plugin as well. The percentage of cells with NF$\kappa \mathrm{B}$ nuclear translocation or NF- $\mathrm{B}$ cytoplasmic retention was determined normalizing the total number of cells with NF- $\mathrm{kB}$ nuclear translocation by the number of cells in the control group.

A microglia morphology analysis was performed based on [34]. Fractal and skeleton analyses were carried out from binary (black and white) images. Using a Fiji image $\mathrm{J}^{\bullet}$ package, several steps were followed to apply commands and options in order to obtain binary images of microglial cells from microphotographs obtained using the epifluorescence microscope. Immunofluorescence with an Iba-1 marker was used to obtain a $\times 40$ microphotograph in grayscale. At least 5 cells from each organ, from each rat, were evaluated with this protocol. Those cells with a complete DAPI staining signal were only included for the analysis. Brightness and contrast were adjusted and an unsharp mask option was applied. To remove "salt and pepper noise", the despeckle filter was applied. To convert the image into binary format, the threshold option was used and adjusted as needed and the noise was subsequently eliminated using despeckle and remove outliers. Then, each cell was selected to be analyzed with the rectangle tool using the region of interest (ROI) to apply the same size rectangle for all selected cells and duplicated in a new window. With the brush tool, the extra signal was removed to leave a single-cell image and later saved as a new file. The new single-cell binary file was used to convert it into an outline or skeletonized format to carry out a fractal and skeleton analysis, respectively.

A fractal analysis was carried out using the plugin FracLac sitting Num $G$ to 4 and the metrics box on the outlined cell from the binary image was checked. Then, the scan was run to obtain the hull and circle results selecting data of interest such as span ratio, radius, circularity and perimeter, and lacunarity was selected from the Box count summary. These parameters allowed us to determine shape differences between LPS treatments to indicate whether a cell was elongated or round. Skeleton analysis was performed on a cell-skeletonized image. The plugin skeleton-analyze skeleton was selected, and the branch information box was checked. The results obtained show information on the number of branches, junctions, and endpoint voxels.

\section{Statistical analyses and antibodies}

Data are expressed as means (3 consecutive sections for the NF-kB p65 nuclear translocation analysis or for the number of microglial cells analyzed morphologically) of the means (4 animals) \pm . For comparisons, a one-way ANOVA followed by the Tukey post hoc test to compare means between groups was carried out. A $p$ value of $<0.05$ was considered statistically significant.

The following antibodies were used: NF-kB p65 was detected with the rabbit monoclonal IgG (8242, Cell Signaling, dilution 1:200) and visualized with the Alexa Fluor 555 conjugate Donkey anti-rabbit (A31572, Life Technologies, dilution 1:1000). Iba-1 was detected with the goat polyclonal IgG (ab5076, Abcam, dilution 1:500) and visualized with Alexa fluor 488 conjugated Donkey anti-goat (A11055, Life Technologies, dilution 1:1000). CD163 was detected with the mouse monoclonal IgG (sc-58965, Santa Cruz, dilution 1:300) and CD45 mouse monoclonal IgG1 (sc-53045, Santa Cruz, dilution 1:200) both visualized with the secondary the Alexa fluor 488 conjugate Donkey anti-mouse IgG (A21202, Life Technologies, dilution 1:1000). NeuN was detected and visualized with the Alexa Fluor ${ }^{\circ} 488$ conjugated mouse monoclonal IgG (MAB377X, Millipore, dilution 1:400). All the primary antibodies were previously proved for their specific antigens $[5,35,36]$.

\section{Results}

NF- $\kappa \mathrm{B}$ is located in different cellular compartments of CVO cells depending on the TLR4 agonist and antagonist lipopolysaccharides administered.

Immunofluorescence images obtained from AP, SFO, and ME of the different LPS treatments showed that NF- $\kappa B$ was retained in the cytoplasm, surrounding the nucleus or translocated into the nucleus, and these events changed according to each experimental group.

A quantitative analysis revealed that treatment with EC-LPS induced an increment of NF- $\mathrm{kB}$ nuclear translocation in the AP compared to control $(p=0.0001)$, PG-LPS $(p=0.0008)$, and RS-LPS $(p<0.0001)$ groups. PG-LPS and RS-LPS treatments tended to increase and decrease the number of cells with NF- $\mathrm{kB}$ nuclear translocation compared to EC-LPS, respectively (Fig. 1e).

$\mathrm{NF}-\mathrm{KB}$ cytoplasmic retention was observed in the three treatments and in the control group. In the AP, 


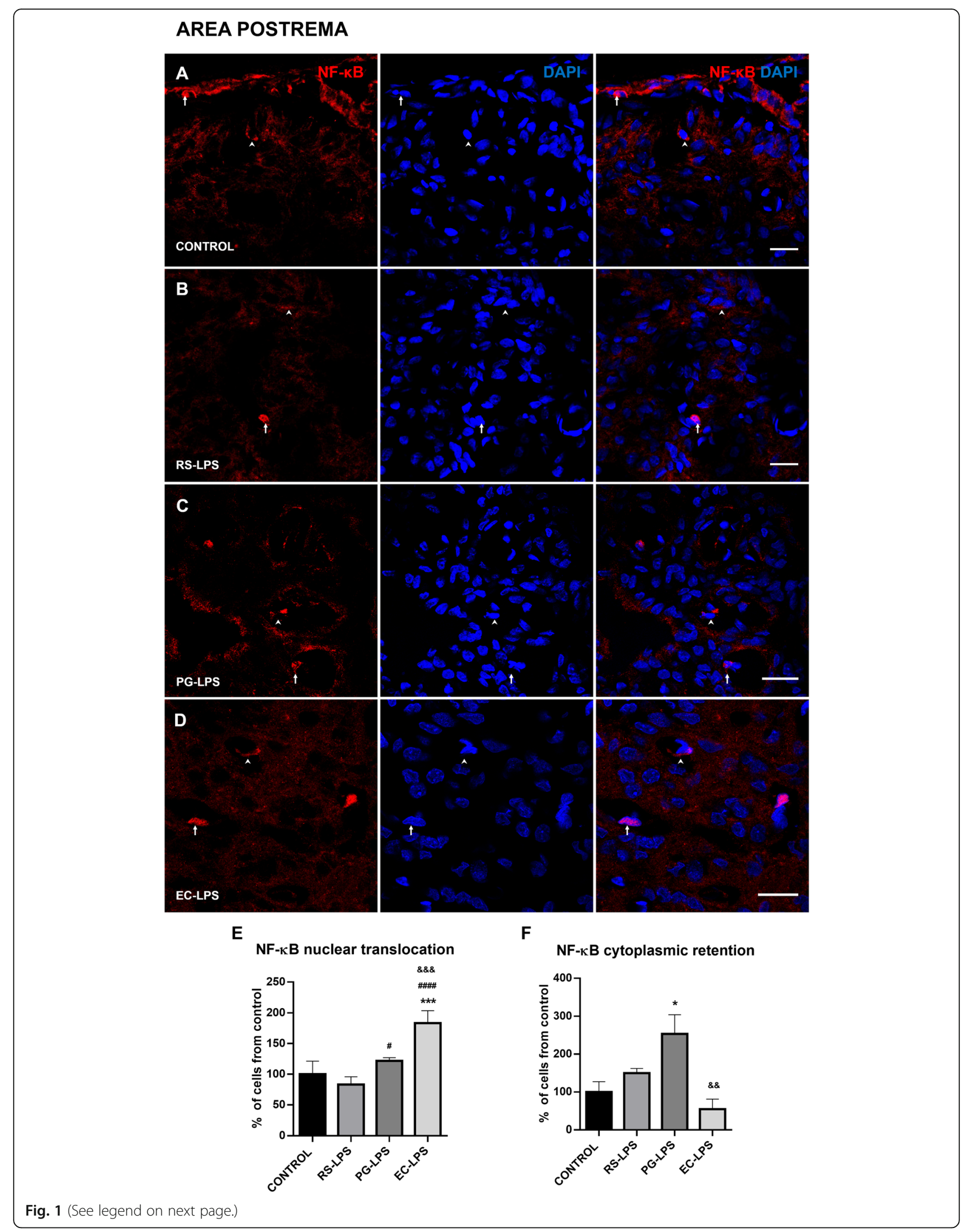


(See figure on previous page.)

Fig. 1 NF-KB cellular localization in the AP of rats i.p. treated with TLR-4 agonists and antagonist LPS. Immunofluorescences of NF-KB in rat AP sections were performed. a The control group, b RS-LPS i.p. group, c PG-LPS i.p. group, and $\mathbf{d}$ EC-LPS i.p. group. In all cases, red corresponds to NF-kB immunosignal and blue DAPI staining in the nucleus. Arrows indicate red and blue immunosignal overlapping or NF-KB nuclear translocation. Head arrows indicate red immunosignal surrounding blue signal NF-KB cytoplasmic retention. Scale bars $=20 \mu m$. e Quantitative analysis of the percentage of NF-KB nuclear translocation. $\mathbf{f}$ Quantitative analysis of the percentage of NF-KB cytoplasmic retention. Data $(n=4)$ were expressed as the mean $\left( \pm\right.$ SEM). ${ }^{*} p<0.05,{ }^{* * *} p<0.001$, vs control. \#p $<0.05$, \#\#\#p $<0.001$ vs RS-LPS. \& $p<0.01, \& \& \& p<0.001$ vs PG-LPS. One-way ANOVA with Tukey's post hoc test

retention in PG-LPS was significantly greater than control and EC-LPS groups (Fig. 1f).

Similarly, NF-kB nuclear translocation in the ECLPS group was greater than control $(p<0.05)$ and RSLPS $(p<0.05)$ groups in the SFO but cytoplasmic retention significantly decreased in PG-LPS $(p<0.005)$ and EC-LPS $(p<0.05)$ compared to control and RSLPS groups (Fig. 2f). Finally, in the ME, it was observed that NF- $\kappa B$ nuclear translocation increased in EC-LPS $(p=0.01)$ and PG-LPS $(p=0.05)$ (Fig. 3e). Cytoplasmic retention of NF- $\mathrm{kB}$ decreased in EC-LPS $(p=0.01)$ and PG-LPS ( $p=0.05)$ (Fig. 3f).

AP, SFO, and ME microglial cells change their morphological shape depending on the TLR4 agonist and antagonist lipopolysaccharides administered.

The microglia marker, Iba-1, was used to evaluate whether morphological changes appear in these cells and their inflammatory response was evaluated through NF- $\mathrm{kB}$ cellular localization (Fig. 4 A-D, Fig. 5 A-D, and Fig. $6 \mathrm{~A}-\mathrm{D})$. The binary and outlined shape were used for fractal analysis in order to evaluate complexity and cell shape. The parameters of radius, circularity, perimeter, lacunarity, and span ratio were useful to measure the distinctive morphology of microglia from the CVOs, not often seen in other well-studied structures such as the frontal cortex.

In the AP, microglia radius registered no significant changes (Fig. 4E). On the other hand, circularity was decreased in the RS-LPS group compared to control ( $p$ $<0.05)$, PG-LPS $(p<0.001)$, and EC-LPS groups $(p<$ 0.001) (Fig. 4F). In the case of perimeter and lacunarity, no significant changes were observed (Fig. 4G, H). The span ratio, a cell shape or elongation measurement was greater in RS-LPS compared to control $(p<0.05)$, PGLPS $(p<0.001)$, and EC-LPS groups $(p<0.001)$ (Fig. $4 \mathrm{I})$. The skeleton analysis was used to evaluate changes in the number of branches, junctions, and endpoints and to determine the effect of the different LPS molecules on the typical ramified structure of the microglial cells. The number of branches was lower in EC-LPS compared to the RS-LPS group $(p<0.05)$ (Fig. 4J). In the case of the number of junctions and endpoints, no changes were observed (Fig. 4K, L).

The effects on morphology changes were observed in SFO and ME as well. In the SFO radius, it was observed that the radius decreased in the EC-LPS group compared to control $(p<0.01)$, RS-LPS $(p<0.01)$, and PG-LPS groups $(p<0.01)$ (Fig. $5 \mathrm{E})$. Circularity was lower in RSLPS group compared to control $(p<0.05)$ and EC-LPS groups $(p<0.01)$ (Fig. $5 \mathrm{~F})$. The perimeter was lower in RS-LPS compared to control $(p<0.01)$ and RS-LPS groups $(p<0.05)$ (Fig. 5G). Lacunarity showed no changes (Fig. $5 \mathrm{H}$ ). In the case of span ratio, the RS-LPS group was significantly greater than control $(p<0.05)$ and EC-LPS groups $(p<0.05)$ (Fig. 5I).

The skeleton analysis showed differences between AP microglial cells. The number of branches was lower in RSLPS $(p<0.05)$, PG-LPS $(p<0.05)$, and EC-LPS groups $(p<$ $0.01)$ compared to the control group (Fig. 5J). The number of junctions was lower in RS-LPS $(p<0.05)$, PG-LPS $(p<$ $0.05)$, and EC-LPS $(p<0.05)$ compared to the control group (Fig. 5K), and the endpoint was lower in RS-LPS ( $p<$ $0.01)$, PG-LPS $(p<0.05)$, and EC-LPS $(p<0.01)$ compared to the control group (Fig. 5L).

In the ME, the radius decreased in the EC-LPS group compared to control $(p<0.05)$, RS-LPS ( $p<$ $0.01)$, and PG-LPS groups $(p<0.001)$ (Fig. 6E). Circularity was lower in the RS-LPS group compared to control $(p<0.001)$, PG-LPS $(p<0.001)$, and EC-LPS groups $(p<0.0001)$ (Fig. 6F). The perimeter was lower in EC-LPS compared to control $(p<0.05)$ and RS-LPS groups $(p<0.01)$, and PG-LPS was also lower than the RS-LPS group $(p<0.01)$ (Fig. 6G). Lacunarity was lower in EC-LPS compared to control $(p<0.01)$ and RS-LPS groups $(p<0.01)$ (Fig. $6 \mathrm{H})$. Span ratio was greater in RS-LPS compared to control $(p<0.001)$, PG-LPS $(p<0.01)$, and EC-LPS groups $(p<0.001)$ (Fig. 6I). The skeleton analysis showed no significant changes between groups in the number of branches, junctions nor endpoints (Fig. 6J-L).

Other cellular types of CVOs have no response to acute i.p. LPS administration.

Aiming to identify other cell types besides microglia that could respond to LPSs, perivascular macrophages, neurons, and circulating leukocytes were identified in the CVOs. In the AP and SFO, no NF- $\mathrm{kB}$ signal was observed in neurons visualized through NeuN marker (Additional file 1: Figure S1 and Figure S2, respectively). In the area of the fenestrated vessel of the ME, no neurons were found (data not shown). In the case of 


\section{SUBFORNICAL ORGAN}
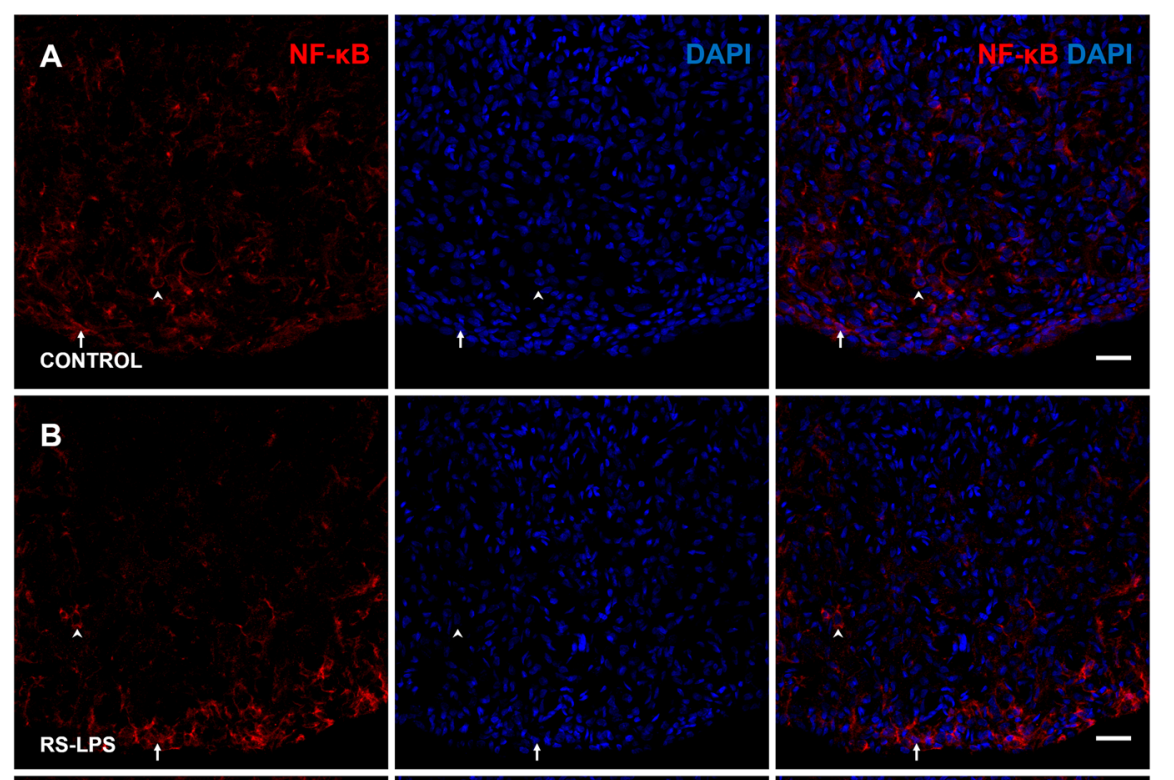

C

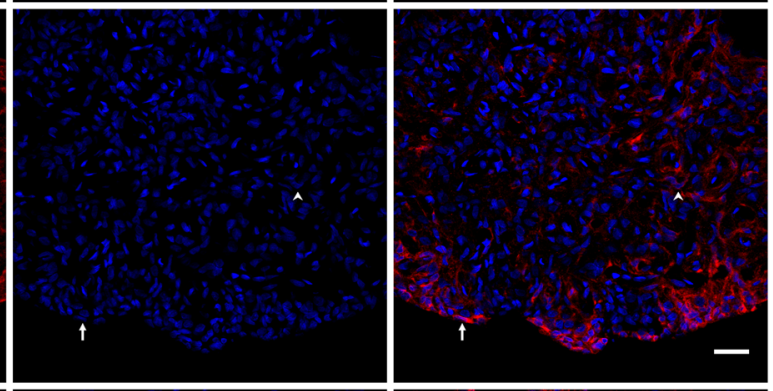

D

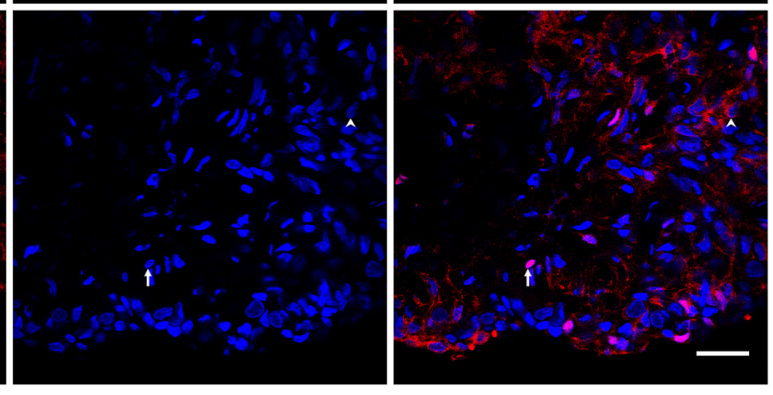

E

$\mathbf{F}$

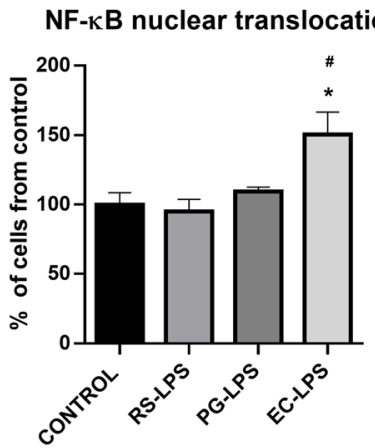

NF-KB cytoplasmic retention

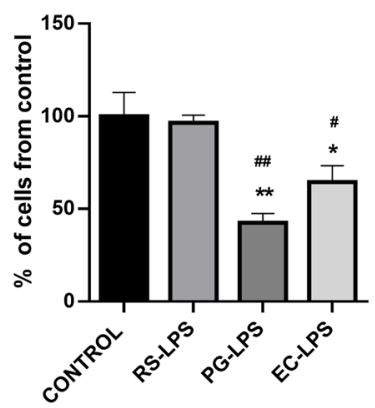

Fig 2 (See legend on next page.) 
(See figure on previous page.)

Fig 2 NF-KB cellular localization in the SFO of rats i.p. treated with TLR-4 agonists and antagonist LPS. Immunofluorescences of NF-KB in rat SFO sections were performed. a The control group, b RS-LPS i.p. group, c PG-LPS i.p. group, and $\mathbf{d}$ EC-LPS i.p. group. In all cases, red corresponds to NF-kB immunosignal and blue DAPI staining in the nucleus. Arrows indicate red and blue immunosignal overlapping or NF-KB nuclear translocation. Head arrows indicate red immunosignal surrounding blue signal NF-KB cytoplasmic retention. Scale bars $=20 \mu m$. e Quantitative analysis of the percentage of NF-KB nuclear translocation. $\mathbf{f}$ Quantitative analysis of the percentage of NF-KB cytoplasmic retention. Data $(n=4)$ were expressed as the mean $\left( \pm\right.$ SEM). ${ }^{*} p<0.05,{ }^{* *} p<0.01$ vs control. $\# p<0.05, \# \# p<0.01$ vs RS-LPS. One-way ANOVA with Tukey's post hoc test

perivascular macrophages, visualized through the CD163 marker, this cell type was present only in the AP and most of the cells registered positive for the NF- $\mathrm{kB}$ signal (Additional file 1: Figure S3), but not in the SFO or in the ME (data not shown). Circulating leukocytes were marked with CD45. This cell type was found only in the $\mathrm{AP}$ and ME (Additional file 1: Figure S4 and Figure S5, respectively). There were no differences in the quantity of leukocyte infiltration between groups, or in NF-kB immunosignal, mainly found translocated in the nucleus in all groups.

\section{Discussion}

This study provides evidence about how bacterial LPSs with different endotoxic properties cause distinct effects on CVOs. Most of the experimental (in vivo or in vitro) studies use LPS derived from E. coli (the highest endotoxic molecule) as an neuroinflammatory inducer; however, in physiological conditions, CVOs might be exposed to LPSs from different gram-negative species present in gut, mouth, or skin microbiota, each of them with different compositions and structures, and with potential to induce high or low inflammatory responses.

Our results of NF- $\mathrm{BB}$ activation in CVOs demonstrate that the immunosignal of this master immune regulator is distributed in the cytoplasm and in the nucleus. Systemic presence of EC-LPS increases nuclear translocation in the three CVOs as several studies have confirmed [37, 38] [4]. However, our study focused on evaluating the effects of an opportunistic bacterial endotoxin such as PG-LPS on the activation of innate immune response mediated by NF- $\mathrm{kB}$ in the CVOs. Results showed that in the secretory CVO ME, PG-LPS induces a statistically significant increase in nuclear translocation, different from the AP and the SFO. In oral epithelial membranes, $P$. gingivalis can up-regulate the expression of downstream genes involved in $T L R / N F-\kappa B-$ driven pro-inflammatory response [39]. Our findings are consistent with [40], showing that, in murine models, PG-LPS induces a weak pro-inflammatory response. These authors state that PG-LPS acts exclusively through TLR4 and is recognized in a different way in mouse and human TLR4 both in vitro and in vivo. The predominant effect of PG-LPS on the ME through NF- $\mathrm{kB}$ nuclear translocation could be related to the fact that this brain region is a secretory CVO and its vascular permeability for low-molecular-mass molecules is higher compared to sensory CVOs such as the AP and SFO [41].

RS-LPS produced no significant effects on the NF-kB nuclear translocation in the CVOs. Studies have revealed that RS-LPS acts a TLR4 antagonist with analgesic properties in a rat neuropathic model, modulating the release of cytokines [42]. Nonetheless, our results suggest that the existing basal immune activation, evaluated through NF- $\kappa \mathrm{B}$ nuclear translocation, in the CVOs was not diminished by the presence of RS-LPS. A recent in vitro study about the effects of RS-LPS in primary mouse microglia demonstrated that this molecule antagonizes EC-LPS when both are co-administrated; however, RSLPS alone efficiently induces the release of cytokines and chemokines in high doses, which depends on TLR4 [27]. The pretreatment with RS-LPS by intracerebroventricular injection did not significantly alter the LPS-induced increase in the number of NF- $\mathrm{KB}$ translocated into the nucleus in microglia of the CVOs [37]. This evidence might corroborate our results according to which systemic administration of RS-LPS has no antagonistic effects in the TLR4 signaling pathway because this could be dependent on a previous inflammatory condition but not on physiological conditions.

An interesting observation was the changes seen in cytoplasmic retention of NF- $\mathrm{kB}$, which occurs in unstimulated cells. NF- $\mathrm{kB}$ dimers reside in the cytoplasm bound to their inhibitory subunit, ІкB. Upon stimulation, IкBs become phosphorylated, subsequently polyubiquitinated and degraded by the proteasome and NF- $\kappa B$ is translocated to the nucleus [43, 44]. Stimulation with EC-LPS induced a decrease of NF- $\mathrm{kB}$ cytoplasmic retention in the three CVOs, and this can be correlated with the increment of $\mathrm{NF}-\mathrm{KB}$ nuclear translocation. In the case of the PG-LPS group, different effects were observed in the CVOs: in the AP, a significant increase in cytoplasm was found, probably related to an overexpression of the subunit p65 as detected in this study [45]; nonetheless, in the SFO and ME, a decrease in cytoplasmic retention of NF-kB effect was observed, similar to EC-LPS. In the ME, cytoplasmic retention in the group of RS-LPS showed no significant changes. 


\section{MEDIAN EMINENCE}

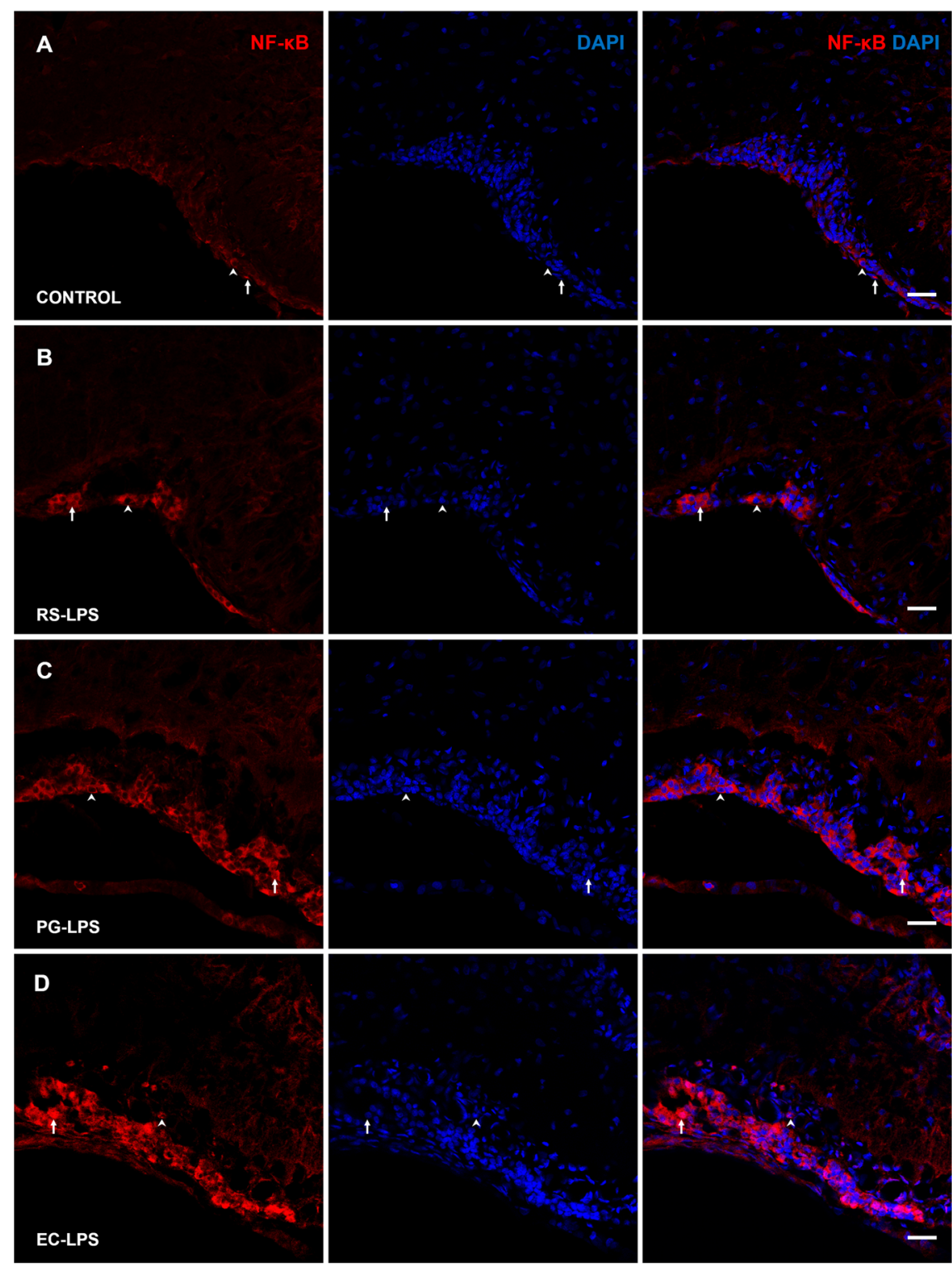

E

NF-кB nuclear translocation

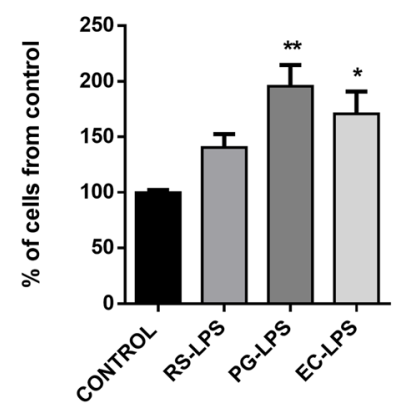

$\mathbf{F}$ NF-kB cytoplasmic retention

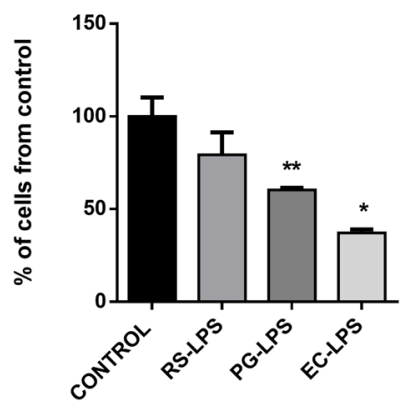

Fig. 3 (See legend on next page.) 
(See figure on previous page.)

Fig. 3 NF-KB cellular localization in the ME of rats i.p. treated with TLR-4 agonists and antagonist LPS. Immunofluorescences of NF-KB in rat ME sections were performed. a The control group, b RS-LPS i.p. group, c PG-LPS i.p. group, and $\mathbf{d}$ EC-LPS i.p. group. In all cases, red corresponds to NF-kB immunosignal and blue DAPI staining in the nucleus. Arrows indicate red and blue immunosignal overlapping or NF-KB nuclear translocation. Head arrows indicate red immunosignal surrounding blue signal NF-KB cytoplasmic retention. Scale bars $=20 \mu m$. e Quantitative analysis of the percentage of NF-KB nuclear translocation. $\mathbf{f}$ Quantitative analysis of the percentage of NF-KB cytoplasmic retention. Data $(n=4)$ were expressed as the mean $( \pm \mathrm{SEM}) .{ }^{*} p<0.05,{ }^{* *} p<0.01$, vs control. One-way ANOVA with Tukey's post hoc test

We have not conducted the usual microglial morphological analysis. Microglia from CVOs are low ramified cells in physiological conditions compared to other brain regions such as the cortex, which made it necessary in this study to analyze parameters based on complexity and shape of the cells using a fractal analysis, such as circularity, radius and perimeter, lacunarity, and span ratio. Circularity determines roundness, increased in amoeboid-like cells. The radius of the cell indicates the maximum radius from the center of the cell, increased in large and elongated cells. The perimeter of the cell can increase or decrease depending on cell shape, whether this is elongated or amoeboid, respectively. Lacunarity refers to the degree of inhomogeneity and translational and rotational invariance in an image, where low lacunarity implies homogeneity and where rotating the image will not change it significantly [45]. Span ratio describes the shape of the outline of the cell where a high span ratio indicates elongation of the cell [46].

EC-LPS group showed significant changes in microglia morphology in the SFO and ME; however, in the AP, the same results tended to be obtained. A lower radius from the center and perimeter indicates that microglial cells exposed to this molecule were smaller than those from the control group. A decrease in lacunarity shows that cells had a homogeneous outline. These significant changes indicate that microglia in the CVOs exposed to EC-LPS tend to have an ameboid shape due to their activation. In other studies, similar results have been obtained after exposure to EC-LPS in the AP where microglia are activated [28] or showed less ramification compared to the adjacent structure, the nucleus of the solitary tract [47]. Administration of PG-LPS did not significantly alter the morphology of microglial cells; however, a tendency was observed in the reduction of radius from the center, perimeter and lacunarity parameters and in all the CVOs tested, as well as in the group of rats injected with EC-LPS. These results indicate that microglia in the CVOs after administration of PG-LPS tend to change their morphology to an ameboid shape. As described by [40], PG-LPS is exclusively recognized by TLR4, inducing low immune activation in mice, and this could be related to low TLR4 and MD2 affinity to Penta-acylated $P$. gingivalis lipid A, producing differences in expression levels of pro-inflammatory molecules. A recent study in mice, injecting $5 \mathrm{mg} / \mathrm{kg}$ (i.p.) of PG-LPS, a higher dose than the one used in our study, reported that microglia in the hippocampus and cortex was activated, and impaired spatial learning and memory in behavioral tests [20]. In addition, it has been described that PG-LPS stimulation is more effective, in terms of cytokine release, in middle-aged mice than young counterparts, which suggests a possible relationship to human adults with periodontal inflammation that can be uncontrollable [48]. Probably, to observe activation of the inflammatory response in the brain caused by PG-LPS, higher doses of this molecule in aged animals would be necessary.

The most unexpected results were the observation of a radical microglial morphological change in the RS-LPS group, an increase of cell radius from the center, loss of circularity, and a significant increase of span ratio, indicating elongation of the cells in all tested CVOs. This type of morphology has been described as "rod" microglia and is associated with brain infections, traumatic brain injury and neurodegenerative disorders [49]. Franz Nissl (1860-1919) and Alois Alzheimer (1864-1915) were the first to describe the presence of rod cells in pathological tissues, but Pío del Río-Hortega (1882-1945) was the first to show that these pathological cells originated from microglia [50]. Nowadays, the function and activity of "rod" microglia are still unknown, although in traumatic brain injury, neuronal damage causes the formation of "rod" microglia promoting astrogliosis and persistent neuroinflammation [51]. In addition, a study carried out in a series of human autopsies showed that older chronological age was a strong predictor for the presence of rod-shaped microglia, even during the control of Alzheimer's disease [52]. Indeed, microglia from CVOs in normal conditions are continuously activated without any pathological stimulation, exhibiting phagocytic and antigen-presenting activities, and even amoeboid form [53]. Thus, the peripheral presence of RS-LPS induces rod-microglia morphology, suggesting a possible noxious effect in microglia function or even in neurons affecting the immune response to immunological and damaging insults.

An interesting finding was to observe that not all microglial cells expressed and translocated the NF- $\mathrm{kB}$ p65 subunit, even in those activated microglia with amoeboid like-shape in the EC-LPS and PG-LPS groups. 


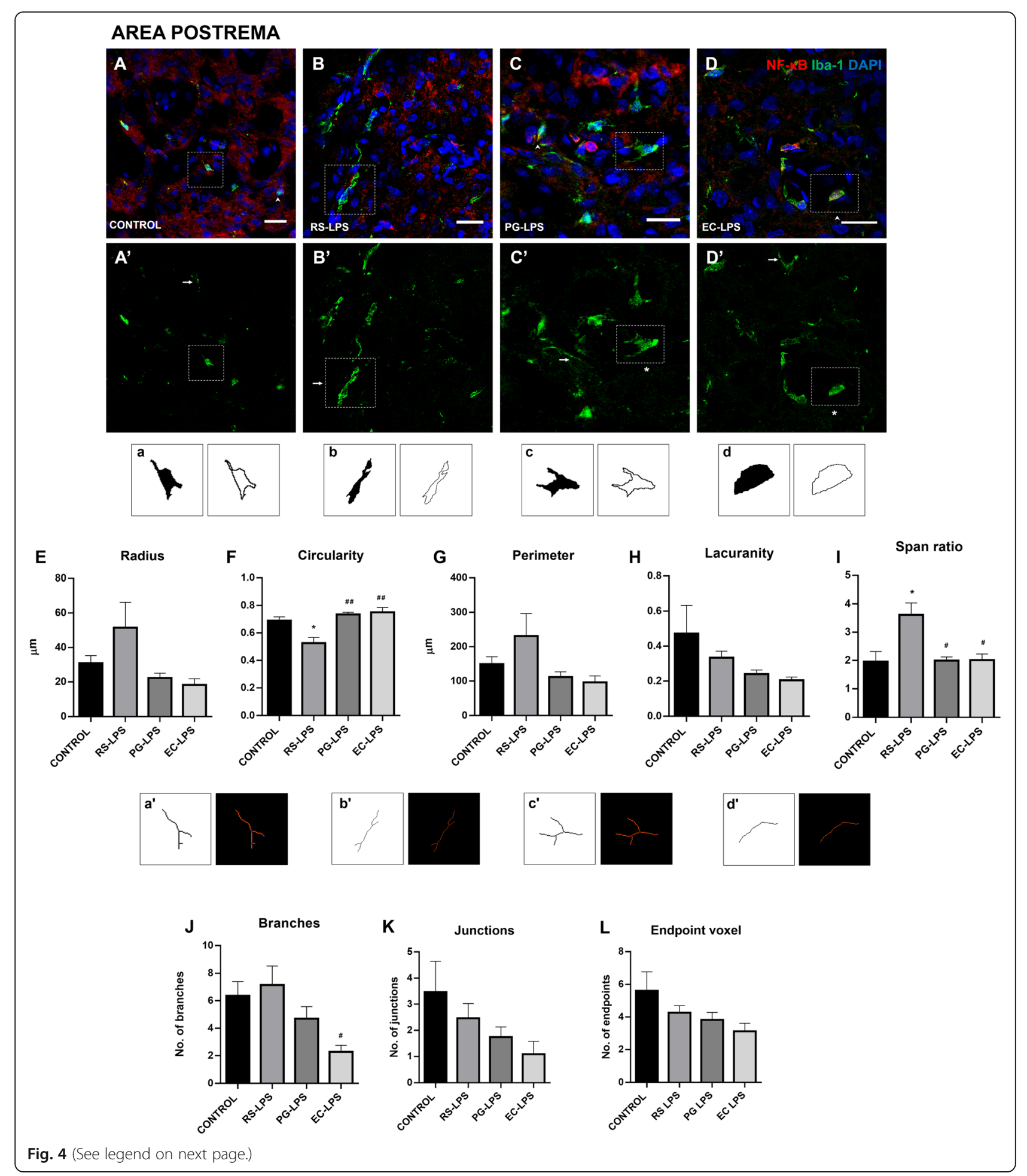


(See figure on previous page.)

Fig. 4 Microglia complexity and ramification in the AP of rats i.p. treated with TLR-4 agonists and antagonist LPS. Immunofluorescence of NF-KB and Iba-1 in rat area postrema sections were performed. A The control group, B RS-LPS i.p. group, C PG-LPS i.p. group, and D EC-LPS i.p. group. In all cases, red corresponds to NF-kB immunosignal, green to iba-1 immunosignal and blue DAPI staining in the nucleus. Scale bars $=20 \mu \mathrm{m}$. Rectangles in dashed line indicate representative cells in each group. $\mathbf{A}^{\prime}, \mathbf{B}^{\prime}, \mathbf{C}^{\prime}$ and $\mathbf{D}^{\prime}$ show only green immune staining. Head arrows indicate NF-KB and Iba-1 positive cells (C and $\mathbf{D}$ panels). Arrows indicate elongated morphology of Iba-1 positive cells ( $\mathbf{A}^{\prime}, \mathbf{B}^{\prime}, \mathbf{C}^{\prime}$ and $\mathbf{D}^{\prime}$ panels). Asterisks indicate ameboid morphology of Iba-1 positive cells indicate ( $\mathbf{C}^{\prime}$ and $\mathbf{D}^{\prime}$ panels). $\mathbf{a}, \mathbf{b}, \mathbf{c}$, and $\mathbf{d}$ binary and outline images of the microglia indicated in the rectangles from images $\mathbf{A}^{\prime}, \mathbf{B}^{\prime}, \mathbf{C}^{\prime}$ and $\mathbf{D}^{\prime}$. Statistical analysis of microglia $\mathbf{E}$ Maximum radius from the center of the cell, $\mathbf{F}$ circularity, G perimeter, $\mathbf{H}$ lacunarity, and I Span ratio. $\mathbf{a}^{\prime}, \mathbf{b}^{\prime}$, $\mathbf{c}^{\prime}$, and $\mathbf{d}^{\prime}$ skeletonized binary images and tag skeletonized processes as orange, endpoints as blue, and junctions as purple of the microglia indicated in the rectangles from images $\mathbf{A}^{\prime}, \mathbf{B}^{\prime}, \mathbf{C}^{\prime}$ and $\mathbf{D}^{\prime}$. Statistical analysis of microglia $\mathbf{J}$ branches $\mathbf{K}$ junctions, and $(\mathbf{L})$ endpoint voxel. Data $(n=4)$ were expressed as the mean $( \pm \mathrm{SEM})$. ${ }^{*} p<0.05$ vs control. \#p $<0.05 \# \# p<$ 0.01 vs RS-LPS. One-way ANOVA with Tukey's post hoc test

It is clear that the three LPS treatments induced effects on microglial morphology; however, LPS signaling over in these cells not necessarily could be related to the canonical NF-kB pathway where p50 and p65 nuclear translocation is produced [54]. It has been described different ways on how LPS can activate an immune response in myeloid and non-myeloid cells, including microglia. For example, the non-canonical NF- $\kappa B$ pathway where p52 and RelB are translocated to the nucleus [55]. In addition, there are other receptors that bind LPS besides the canonical TLR-4. Caspases 4/5/11 are cytosolic LPS receptors, activating through oligomerization with LPS [56]. The receptor for advanced glycation end products (RAGE) can interact with LPS, and this receptor can be responsible for microglial activation and production of proinflammatory mediators in Alzheimer's disease [57]. This evidence could explain the other type of LPS interaction with microglia without the activation of the canonical NF- $\mathrm{kB}$ activation pathway, and the possible LPS binding to other receptors which could be able also to recognize different structures and composition of this bacterial molecule.

There is evidence of harmful microbiota-derived TLR4 antagonistic LPS effects on health promoting the development of autoimmune diseases. In a recent study, it has been found that LPS from Bacteroides dorei with TLR4 antagonist properties was abundant in children from countries with an early onset of autoimmune disease. Conversely, LPS from E. coli was more prevalent, and prevented the development of the autoimmune disease. The main conclusion of this study was that agonistic LPS with endotoxic properties can prevent autoimmune disease by immuno-stimulation and socalled "endotoxin tolerance" is a factor that contributes to a better "immune education". On the contrary, antagonistic LPS inhibits immune stimulation and the inflammatory response from other agonist LPS molecules [58].

EC-LPS i.p. or i.c.v. administration is among the most common models of neuroinflammation induction [59]. However, few studies have referred to the effects of a limited variety of LPS molecules and their endotoxic properties in the brain immune response. Our research group has recently shown the infiltration of LPS in the brain possibly transported by plasma lipoproteins, in physiological conditions, in blood-brain-interfaces such as CVOs [5], and recently, the presence of uncovered bacteria in healthy individuals has been reported [48]. These evidences suggest a necessary re-evaluation of the theory of a sterile brain and the immunological privilege of this organ. A microorganism from microbiota or from infections can act directly on the brain through the most abundant molecule in gram-negative bacteria, LPS, modulating the inflammatory response by shaping glial activity. Possibly, the CNS is not excluded from "immune education" by composition microbiota as occurs in the periphery, more specifically, a variation of LPS TLR4 agonistic and antagonistic functions could be responsible for brain immune defense in health and disease.

Further studies about the role of TLR4 agonist and antagonist LPS in the CNS immunity will require to evaluate other types of LPS from different human microbiota gram-negative bacteria involved in healthy and pathological conditions to elucidate their mechanism in the inflammatory response.

In addition, it will be necessary to evaluate the effect of the LPS molecules used in this study on different time stages to assess the response of different inflammatory pathways besides the canonical NF- $\mathrm{kB}$ pathway.

It will be also needed a chronic administration to analyze these molecules tolerance response in brain immunity, as well as, to analyze their effect on parenchymal structures, such as the brain cortex and hippocampus.

\section{Conclusions}

In conclusion, our results, as well as other studies, demonstrated that the canonical TLR4 agonist, EC-LPS, activates the inflammatory response in the CVOs through NF- $\mathrm{kB}$ and microglia activation, changing their morphology to an ameboid shape. On the other hand, PG-LPS, as a mild TLR4 agonist, only induced NF- $\mathrm{kB}$ nuclear translocation in the ME, probably because this secretory CVO has a higher vascular permeability compared to 


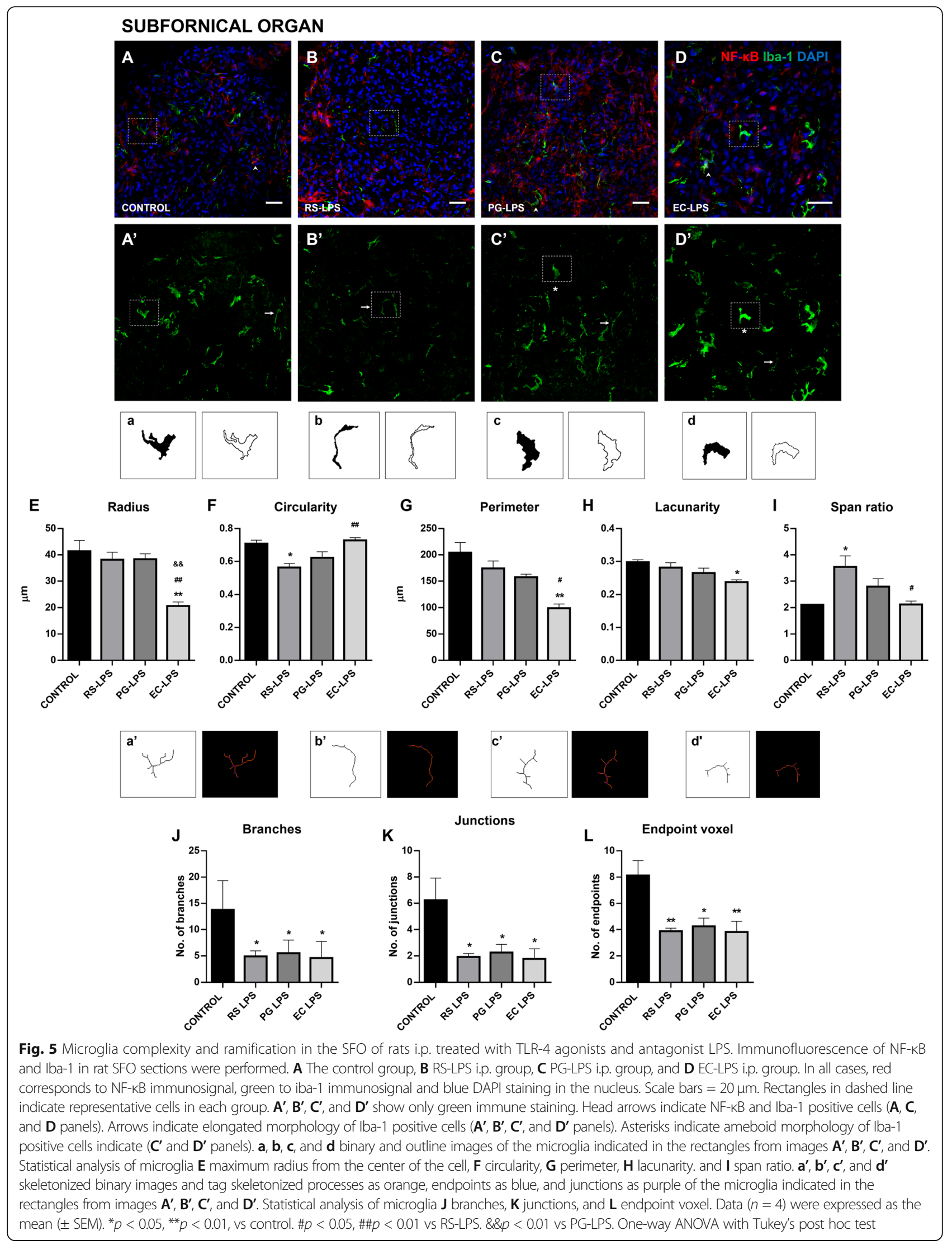




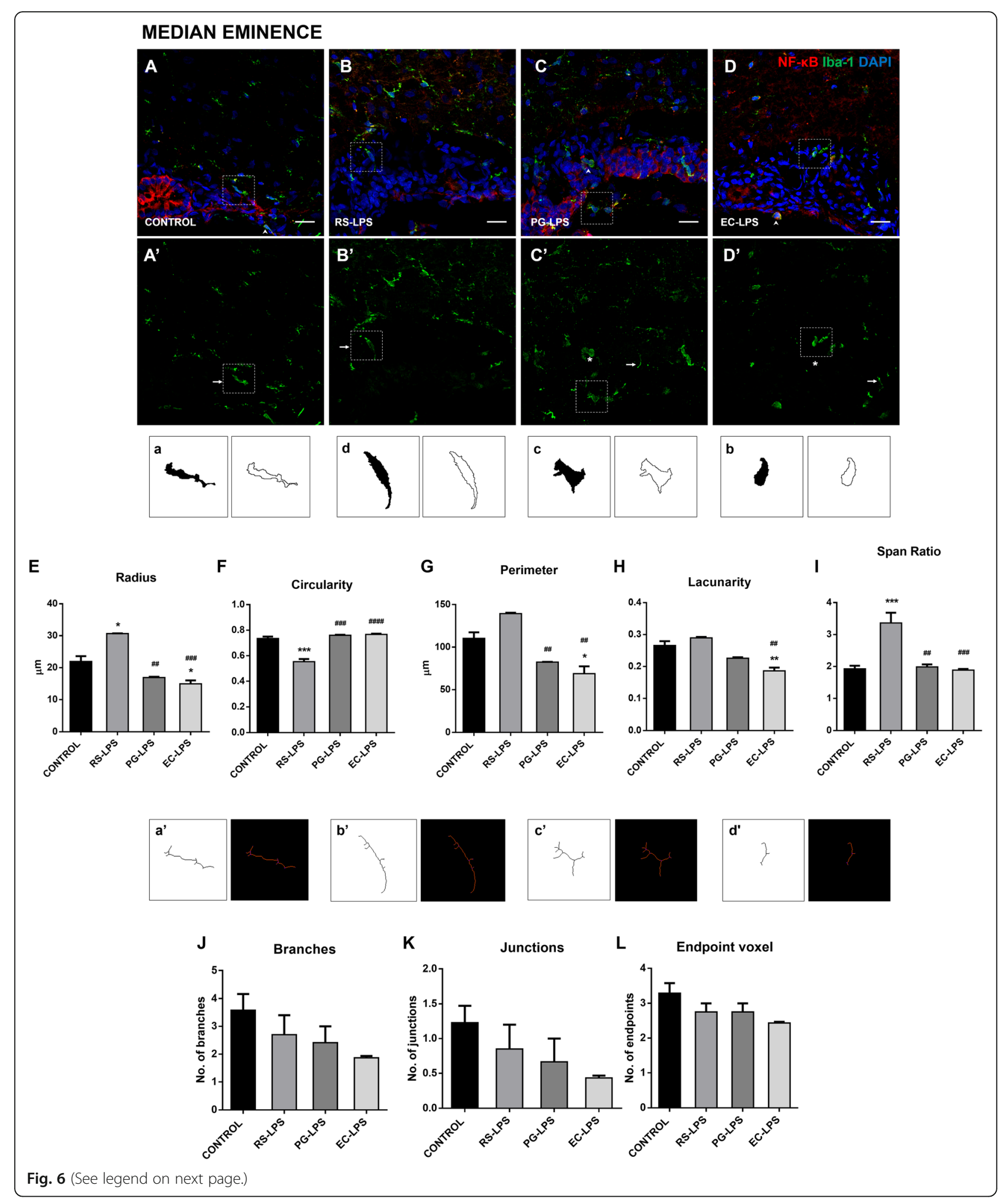


(See figure on previous page.)

Fig. 6 Microglia complexity and ramification in the ME of rats i.p. treated with TLR-4 agonists and antagonist LPS. Immunofluorescence of NF-KB and Iba-1 in rat ME sections were performed. A The control group, B RS-LPS i.p. group, C PG-LPS i.p. group, and D EC-LPS i.p. group. In all cases, red corresponds to NF-KB immunosignal, green to iba-1 immunosignal and blue DAPI staining in the nucleus. Scale bars $=20 \mu \mathrm{m}$. Rectangles in dashed line indicate representative cells in each group. $\mathbf{A}^{\prime}, \mathbf{B}^{\prime}, \mathbf{C}^{\prime}$, and $\mathbf{D}^{\prime}$ show only green immune staining. Head arrows indicate NF-KB and Iba1 positive cells (A, C, and $\mathbf{D}$ panels). Arrows indicate elongated morphology of Iba-1 positive cells ( $\mathbf{A}^{\prime}, \mathbf{B}^{\prime}, \mathbf{C}^{\prime}$, and $\mathbf{D}^{\prime}$ panels). Asterisks indicate ameboid morphology of Iba-1 positive cells indicate ( $\mathbf{C}^{\prime}$ and $\mathbf{D}^{\prime}$ panels). $\mathbf{a}, \mathbf{b}, \mathbf{c}$, and $\mathbf{d}$ binary and outline images of the microglia indicated in the rectangles from images $\mathbf{A}^{\prime}, \mathbf{B}^{\prime}, \mathbf{C}^{\prime}$, and $\mathbf{D}^{\prime}$. Statistical analysis of microglia $\mathbf{E}$ maximum radius from the center of the cell, $\mathbf{F}$ circularity, $\mathbf{G}$ perimeter, $\mathbf{H}$ lacunarity, and I span ratio. $\mathbf{a}^{\prime}, \mathbf{b}^{\prime}, \mathbf{c}^{\prime}$, and $\mathbf{d}^{\prime}$ skeletonized binary images and tag skeletonized processes as orange, endpoints as blue, and junctions as purple of the microglia indicated in the rectangles from images $\mathbf{A}^{\prime}, \mathbf{B}^{\prime}, \mathbf{C}^{\prime}$, and $\mathbf{D}^{\prime}$. Statistical analysis of microglia $\mathbf{J}$ branches, $\mathbf{K}$ junctions, and $\mathbf{L}$ endpoint voxel. Data $(n=4)$ were expressed as the mean $\left( \pm\right.$ SEM). ${ }^{*} p<0.05,{ }^{* *} p<0.01,{ }^{* * *} p<0.001$, vs control. \#\#p $<0.01$, \#\#\#p $<0.001$ vs RS-LPS. One-way ANOVA with Tukey's post hoc test

sensory CVOs. There was only a tendency to change microglial morphology into an ameboid shape by PGLPS administration, maybe because concentration and immune deficiency by aging are involved to induce an inflammatory response in the brain. On the contrary, RS-LPS did not change NF- $\mathrm{kB}$ activation in the CVOs. Interestingly, this TLR4 antagonist induced a rod microglia shape, a type of morphology found in severe pathological situations such as traumatic brain injury, infections, or neurodegenerative diseases. Microbiota variation leading to an imbalance, where TLR4 antagonist LPS molecules are increased compared to TLR4 agonist ones, could lead to the development of neurological conditions where rod microglia are involved. The therapeutic use of TLR4 antagonist from LPS or synthetic molecules to treat neuroinflammatory conditions should be carefully revised since the inflammatory response is a strategy of the immune system to attack immunological and damaging insults, microglia activation and NF- $\mathrm{kB}$ nuclear translocation in the CVOs are normally present, perhaps because these structures play the role of the first line of immune defense in the brain.

\section{Supplementary information}

Supplementary information accompanies this paper at https://doi.org/10. 1186/s12974-019-1690-2.

Additional file 1: Supplementary information.

\section{Acknowledgements}

Confocal images were obtained in the Centro de Asistencia a la Investigación (CAI) Técnicas Biológicas, Universidad Complutense de Madrid (UCM).

\section{Authors' contributions}

AVC designed the study, performed immunofluorescence and wrote the first draft of the paper; AS carried out the animal work and prepared samples and JR prepared samples; JRC and JLMM discussed the protocols and results; $B G B$ and JCL discussed the whole project. All authors were involved in the final version of the paper. All authors read and approved the final manuscript.

\section{Funding}

This work was supported by MINECO-FEDER Funds (SAF2016-75500-R and SAF2017-85888-R) and CIBERSAM. AVC is a postdoctoral fellow of CONACYT (Mexico). JRC is a Ramón y Cajal programme fellow (MINECO, Spain).

\section{Availability of data and materials}

The datasets used and/or analyzed during the current study are available from the corresponding author on reasonable request.

\section{Ethics approval and consent to participate}

All experimental procedures adhered to the guidelines of the Animal Welfare Committee of the Universidad Complutense (PROEX099/19) following European legislation (2010/63/EU) and they were carried out in the Animal Facility CAI-UCM. Animal studies are reported in compliance with the ARRIVE guidelines and all efforts were made to minimize animal suffering and to reduce the number of animals used.

\section{Consent for publication}

Not applicable

\section{Competing interests}

The authors declare that they have no competing interests.

\section{Author details}

'Departamento de Farmacología y Toxicología, Facultad de Medicina, Universidad Complutense de Madrid (UCM); Centro de Investigación Biomédica en Red de Salud Mental (CIBERSAM); Instituto de Investigación Sanitaria Hospital 12 de Octubre (Imas12); Instituto Universitario de Investigación en Neuroquímica UCM, Avda. Complutense s/n, 28040 Madrid, Spain. ${ }^{2}$ Biological and Health Sciences Division, Metropolitan Autonomous University (UAM), Campus Lerma, 52005 Lerma, Mexico.

Received: 19 September 2019 Accepted: 23 December 2019

Published online: 06 January 2020

\section{References}

1. Siso S, Jeffrey M, Gonzalez L. Sensory circumventricular organs in health and disease. Acta Neuropathologica. 2010;120:689-705.

2. Mullier A, Bouret SG, Prevot V, Dehouck B. Differential distribution of tight junction proteins suggests a role for tanycytes in blood-hypothalamus barrier regulation in the adult mouse brain. J Comp Neurol. 2010;518: 943-62.

3. Wuchert F, Ott D, Murgott J, Rafalzik S, Hitzel N, Roth J, Gerstberger R. Rat area postrema microglial cells act as sensors for the toll-like receptor-4 agonist lipopolysaccharide. J Neuroimmunol. 2008;204:66-74.

4. Xia Y, Yamagata K, Krukoff TL. Differential expression of the CD14/TLR4 complex and inflammatory signaling molecules following i.c.V. administration of LPS. Brain Res. 2006;1095:85-95.

5. Vargas-Caraveo A, Sayd A, Maus SR, Caso JR, Madrigal JLM, Garcia-Bueno B, Leza JC. Lipopolysaccharide enters the rat brain by a lipoprotein-mediated transport mechanism in physiological conditions. Sci Rep. 2017;7:13113.

6. Jeong HK, Jou I, Joe EH. Systemic LPS administration induces brain inflammation but not dopaminergic neuronal death in the substantia nigra. Exp Mol Med. 2010;42:823-32.

7. Lin HC, Wan FJ, Kang BH, Wu CC, Tseng CJ. Systemic administration of lipopolysaccharide induces release of nitric oxide and glutamate and c-fos expression in the nucleus tractus solitarii of rats. Hypertension. 1999;33: 1218-24.

8. Maes M, Mihaylova I, Kubera M, Leunis JC. An IgM-mediated immune response directed against nitro-bovine serum albumin (nitro-BSA) in chronic 
fatigue syndrome (CFS) and major depression: evidence that nitrosative stress is another factor underpinning the comorbidity between major depression and CFS. Neuro Endocrinol Lett. 2008;29:313-9.

9. Delaney S, Fallon B, Alaedini A, Yolken R, Indart A, Feng TS, Wang YJ, Javitt D. Inflammatory biomarkers in psychosis and clinical high risk populations. Schizophrenia Res. 2019;206:440-3.

10. Raetz CRH, Reynolds CM, Trent MS, Bishop RE. Lipid a modification systems in gram-negative bacteria. Annu Rev Biochem. 2007;76:295-329.

11. Needham BD, Trent MS. Fortifying the barrier: the impact of lipid A remodelling on bacterial pathogenesis. Nat Rev Microbiol. 2013;11:467-81.

12. Molinaro A, Holst O, Di Lorenzo F, Callaghan M, Nurisso A, D'Errico G, Zamyatina A, Peri F, Berisio R, Jerala R, et al. Chemistry of Lipid A: At the Heart of Innate Immunity. Chemistry. 2015;21:500-19.

13. Netea MG, van Deuren M, Kullberg BJ, Cavaillon JM, Van der Meer JWM. Does the shape of lipid A determine the interaction of LPS with Toll-like receptors? Trends Immunol. 2002;23:135-9.

14. Munford RS. Endotoxemia-menace, marker, or mistake? J Leukocyte Biol. 2016;100:687-98.

15. Dominy SS, Lynch C, Ermini F, Benedyk M, Marczyk A, Konradi A, Nguyen M, Haditsch U, Raha D, Griffin C, et al. Porphyromonas gingivalis in Alzheimer's disease brains: Evidence for disease causation and treatment with smallmolecule inhibitors. Sci Adv. 2019;5.

16. Adams CE, Wells NC, Clifton A, Jones H, Simpson J, Tosh G, Callaghan P, Liddle P, Guo BL, Furtado V, et al. Monitoring oral health of people in Early Intervention for Psychosis (EIP) teams: The extended Three Shires randomised trial. Int J Nurs Stud. 2018;77:106-14.

17. Nascimento GG, Gastal MT, Leite FRM, Quevedo LA, Peres KG, Peres MA, Horta BL, Barros FC, Demarco FF. Is there an association between depression and periodontitis? A birth cohort study. J Clin Periodontol. 2019; 46:31-9.

18. Ding Y, Ren J, Yu H, Yu W, Zhou Y. Porphyromonas gingivalis, a periodontitis causing bacterium, induces memory impairment and agedependent neuroinflammation in mice. Immun Ageing. 2018;15:6.

19. Wang YX, Kang XN, Cao Y, Zheng DX, Lu YM, Pang CF, Wang Z, Cheng B, Peng Y. Porphyromonas gingivalis induces depression via downregulating p75NTR-mediated BDNF maturation in astrocytes. Brain Behav Immun. 2019; 81:523-34.

20. Zhang J, Yu CB, Zhang X, Chen HW, Dong JC, Lu WL, Song ZC, Zhou W. Porphyromonas gingivalis lipopolysaccharide induces cognitive dysfunction, mediated by neuronal inflammation via activation of the TLR4 signaling pathway in C57BL/6 mice. J Neuroinflamm. 2018;15(1):37.

21. Anwar MA, Panneerselvam S, Shah M, Choi S. Insights into the speciesspecific TLR4 signaling mechanism in response to Rhodobacter sphaeroides lipid A detection. Sci Rep. 2015;5.

22. Gaikwad S, Agrawal-Rajput R. Lipopolysaccharide from Rhodobacter sphaeroides attenuates microglia-mediated inflammation and phagocytosis and directs regulatory T Cell response. Int J Inflamm. 2015.

23. Molteni M, Bosi A, Rossetti C. Natural products with Toll-like receptor 4 antagonist activity. Int J Inflamm. 2018.

24. Yang XL, Zhang JD, Duan L, Xiong HG, Jiang YP, Liang HC. Microglia activation mediated by toll-like receptor-4 impairs brain white matter tracts in rats. J Biomed Res. 2018;32:136-44.

25. Rodgers KM, Hutchinson MR, Northcutt A, Maier SF, Watkins LR, Barth DS. The cortical innate immune response increases local neuronal excitability leading to seizures. Brain. 2009:132:2478-86.

26. Jurga AM, Rojewska E, Piotrowska A, Makuch W, Pilat D, Przewlocka B, Mika J. Blockade of Toll-like receptors (TLR2, TLR4) attenuates pain and potentiates buprenorphine analgesia in a rat neuropathic pain model. Neural Plasticity. 2016.

27. Doring C, Regen T, Gertig U, van Rossum D, Winkler A, Saiepour N, Bruck W, Hanisch UK, Janova H. A presumed antagonistic LPtpdeS identifies distinct functional organization of TLR4 in mouse microglia. Glia. 2017;65:1176-85.

28. Lee $\mathrm{S}$, Zhao YQ, Ribeiro-da-Silva A, Zhang J. Distinctive response of CNS glial cells in oro-facial pain associated with injury, infection and inflammation. Mol Pain. 2010;6:79.

29. MacDowell KS, Garcia-Bueno B, Madrigal JLM, Parellada M, Arango C, Mico $J A$, Leza JC. Risperidone normalizes increased inflammatory parameters and restores anti-inflammatory pathways in a model of neuroinflammation. Int J Neuropsychopharmacol. 2013;16:121-35.

30. Sayd A, Anton M, Alen F, Caso JR, Pavon J, Leza JC, de Fonseca FR, GarciaBueno B, Orio L. Systemic Administration of oleoylethanolamide protects from neuroinflammation and anhedonia induced by LPS in rats. Int J Neuropsychopharmacol. 2015;18.

31. Nakano Y, Furube E, Morita S, Wanaka A, Nakashima T, Miyata S. Astrocytic TLR4 expression and LPS-induced nuclear translocation of STAT3 in the sensory circumventricular organs of adult mouse brain. J Neuroimmunol. 2015;278:144-58

32. Laflamme N, Rivest S. Toll-like receptor 4: the missing link of the cerebral innate immune response triggered by circulating gram-negative bacterial cell wall components. Faseb J. 2001;15:155-63.

33. Rummel C. Inflammatory transcription factors as activation markers and functional readouts in immune-to-brain communication. Brain Behav Immun. 2016;54:1-14.

34. Morrison H, Young K, Qureshi M, Rowe RK, Lifshitz J. Quantitative microglia analyses reveal diverse morphologic responses in the rat cortex after diffuse brain injury. Sci Rep. 2017:7:13211.

35. Martin-Hernandez D, Caso JR, Bris AG, Maus SR, Madrigal JL, Garcia-Bueno B, MacDowell KS, Alou L, Gomez-Lus ML, Leza JC. Bacterial translocation affects intracellular neuroinflammatory pathways in a depression-like model in rats. Neuropharmacology. 2016:103:122-33.

36. Gutierrez IL, Gonzalez-Prieto M, Caso JR, Garcia-Bueno B, Leza JC, Madrigal JLM. Reboxetine treatment reduces neuroinflammation and neurodegeneration in the 5xFAD mouse model of Alzheimer's Disease: Role of CCL2. Mol Neurobiol. 2019.

37. Muneoka S, Murayama S, Nakano Y, Miyata S. TLR4 in circumventricular neural stem cells is a negative regulator for thermogenic pathways in the mouse brain. J Neuroimmunol. 2019:331:58-73.

38. Nadeau S, Rivest $\mathrm{S}$. Role of microglial-derived tumor necrosis factor in mediating CD14 transcription and nuclear factor kappa B activity in the brain during endotoxemia. J Neurosci. 2000;20:3456-68.

39. Groeger $\mathrm{S}$, Jarzina $\mathrm{F}$, Domann E, Meyle J. Porphyromonas gingivalis activates NFkappaB and MAPK pathways in human oral epithelial cells. BMC Immunol. 2017:18:1.

40. Nativel B, Couret D, Giraud P, Meilhac O, d'Hellencourt CL, Viranaicken W, Da Silva CR. Porphyromonas gingivalis lipopolysaccharides act exclusively through TLR4 with a resilience between mouse and human. Sci Rep. 2017:7:15789.

41. Morita S, Miyata S. Different vascular permeability between the sensory and secretory circumventricular organs of adult mouse brain. Cell Tiss Res. 2012; 349:589-603.

42. Jurga AM, Rojewska E, Makuch W, Mika J. Lipopolysaccharide from Rhodobacter sphaeroides (TLR4 antagonist) attenuates hypersensitivity and modulates nociceptive factors. Pharmaceutical Biology. 2018;56:275-86.

43. Beg AA, Ruben SM, Scheinman RI, Haskill S, Rosen CA, Baldwin AS. I-Kappa-B Interacts with the Nuclear-Localization Sequences of the Subunits of Nf-Kappa-B - a Mechanism for Cytoplasmic Retention. Genes Dev. 1992;6:1899-913.

44. Chen ZJ, Hagler J, Palombella VJ, Melandri F, Scherer D, Ballard D, Maniatis T. Signal-Induced site-specific phosphorylation targets I-Kappa-B-alpha to the ubiquitin-proteasome pathway. Genes Dev. 1995:9:1586-97.

45. Koshimizu JY, Beltrame FL, de Pizzol JP, Cerri PS, Caneguim BH, Sasso-Cerri E. NF-kB overexpression and decreased immunoexpression of AR in the muscular layer is related to structural damages and apoptosis in cimetidinetreated rat vas deferens. Reprod Biol Endocrinol. 2013:11.

46. Young K, Morrison H. Quantifying microglia morphology from photomicrographs of immunohistochemistry prepared tissue using ImageJ. J Vis Exp. 2018.

47. Konsman JP, Kelley K, Dantzer R. Temporal and spatial relationships between lipopolysaccharide-induced expression of fos, interleukin-1 beta and inducible nitric oxide synthase in rat brain. Neuroscience. 1999;89:535-48.

48. Sun Y, Li H, Yang MF, Shu W, Sun MJ, Xu Y. Effects of aging on endotoxin tolerance induced by lipopolysaccharides derived from Porphyromonas gingivalis and Escherichia coli. PLoS One. 2012;7:e39224.

49. Au NPB. Ma CHE: Recent advances in the study of bipolar/rod-shaped microglia and their roles in neurodegeneration. Front Aging Neurosci. 2017: 9:128

50. Sierra A, de Castro F, Del Rio-Hortega J, Rafael Iglesias-Rozas J, Garrosa M, Kettenmann H. The "Big-Bang" for modern glial biology: Translation and comments on Pio del Rio-Hortega 1919 series of papers on microglia. Glia. 2016;64:1801-40.

51. Witcher KG, Bray CE, Dziabis JE, McKim DB, Benner BN, Rowe RK, KokikoCochran ON, Popovich PG, Lifshitz J, Eiferman DS, Godbout JP. Traumatic 
brain injury-induced neuronal damage in the somatosensory cortex causes formation of rod-shaped microglia that promote astrogliosis and persistent neuroinflammation. Glia. 2018;66:2719-36.

52. Bachstetter AD, Ighodaro ET, Hassoun $Y$, Aldeiri $D$, Neltner JH, Patel E, Abner EL, Nelson PT. Rod-shaped microglia morphology is associated with aging in 2 human autopsy series. Neurobiol Aging. 2017:52:98-105.

53. Takagi S, Furube E, Nakano Y, Morita M, Miyata S. Microglia are continuously activated in the circumventricular organs of mouse brain. J Neuroimmunol. 2019;331:74-86

54. Sun SC. The non-canonical NF-kappaB pathway in immunity and inflammation. Nat Rev Immunol. 2017:17:545-58.

55. Shih RH, Wang CY, Yang CM. NF-kappaB signaling pathways in neurological inflammation: a mini review. Front Mol Neurosci. 2015;8:77.

56. Smith C, Wang XH, Yin H. Caspases come together over LPS. Trend Immunol. 2015:36:59-61.

57. Yu Y, Ye RD. Microglial Abeta receptors in Alzheimer's disease. Cell Mol Neurobiol. 2015;35:71-83.

58. Vatanen T, Kostic AD, d'Hennezel E, Siljander H, Franzosa EA, Yassour M, Kolde R, Vlamakis H, Arthur TD, Hamalainen AM, et al. Variation in microbiome LPS Immunogenicity contributes to autoimmunity in humans (vol 165, pg 842, 2016). Cell. 2016;165:1551.

59. Catorce MN, Gevorkian G. LPS-induced murine neuroinflammation model: main features and suitability for pre-clinical assessment of nutraceuticals. Curr Neuropharmacol. 2016;14:155-64.

\section{Publisher's Note}

Springer Nature remains neutral with regard to jurisdictional claims in published maps and institutional affiliations.

Ready to submit your research? Choose BMC and benefit from:

- fast, convenient online submission

- thorough peer review by experienced researchers in your field

- rapid publication on acceptance

- support for research data, including large and complex data types

- gold Open Access which fosters wider collaboration and increased citations

- maximum visibility for your research: over $100 \mathrm{M}$ website views per year

At BMC, research is always in progress.

Learn more biomedcentral.com/submissions 